\title{
Los memes políticos como recurso persuasivo online. Análisis de su repercusión durante los debates electorales de 2019 en España
}

\author{
Rocio Zamora Medina ${ }^{1}$ (D) \\ Salvador Gómez García ${ }^{2}$ \\ Helena Martínez Martínez ${ }^{3}$ (iD)
}

\begin{abstract}
En el contexto del politainment online, el recurso de los memes políticos como fórmula humorística y creativa para configurar la imagen política se ha convertido en una práctica cada vez más habitual en las campañas electorales. Especialmente con motivo de la celebración de debates electorales, la difusión de memes políticos en redes sociales ha acaparado el interés de los académicos. Este artículo toma en consideración las taxonomías establecidas sobre los tipos de memes políticos y analiza su capacidad persuasiva. En concreto, la investigación incluye un análisis cuantitativo de los principales memes difundidos en Twitter durante los dos debates electorales que tuvieron lugar en la campaña electoral de 2019 en España: 4N y 7N. El estudio está fundamentado en la perspectiva del framing integrado (textualvisual) y se sustenta sobre el estudio del poder persuasivo de los memes basado en la importancia de cada uno de los elementos de la retórica (pathos, ethos y logos) con el objetivo de analizar, asimismo, las consecuencias sobre su viralidad y repercusión en la audiencia social.
\end{abstract}

Palabras clave: memes; redes sociales; campañas electorales; Twitter; humor; España

\section{Introducción}

El cruce de caminos entre la comunicación política, la viralidad y el humor en el escenario digital ha ido incrementándose a lo largo del tiempo (Highfield, 2016; GómezGarcía et al., 2019). La proliferación de canales que privilegian el uso de la parodia, el contenido sarcástico, gifs, memes o otros contenidos burlescos, los ha convertido en un elemento fundamental no sólo del debate político contemporáneo, también de un

\footnotetext{
1 Universidad de Murcia. Facultad de Comunicación y Documentación. Murcia, Espanha.

E-mail: <rzamoramedina@um.es>.

2 Universidad de Valladolid. Facultad de Filosofía y Letras. Valladolid, Castilla y León, Espanha.

E-mail: <salvadorgomez@hmca.uva.es>.

3 Universidad de Murcia. Facultad de Comunicación y Documentación. Murcia, Espanha.

E-mail: <helenamartinez@um.es>.
} 
tratamiento habitual en los escenarios de crisis sociales, sanitarias y económicas más recientes (Manfredi-Sánchez, Amado-Suárez y Waisbord, 2021). En ese sentido, Davis, Love y Killen (2018) han definido este nuevo contexto en la convergencia de tres vectores claramente diferenciados: el incremento de los espacios satíricos de actualidad (Webber, Sarlos y Eckhardt, 2013), un entorno de medios participativos impulsado por las tecnologías sociales digitales (Barnard, 2016) y, por último, la consolidación de una cultura de creadores a través de internet en la que el ingenio es un activo indispensable (NavarroSierra y Quevedo-Redondo, 2020). Este uso del humor también ha propiciado un prolífico corpus de investigaciones que, si bien señala su carácter distintivo, todavía no ha profundizado en las fórmulas en las que este se manifiesta.

El presente artículo se sitúa en las coordenadas anteriores para abordar un escenario concreto: la popularidad de los memes como estrategia a medio camino entre lo humorístico, lo informativo y lo político, para participar en el debate de la campaña política que se desarrolló durante el mes de noviembre de 2019 en España. Esta investigación sobre el uso de memes en el marco de los debates electorales, percibidos como una prueba de fuego para los candidatos y los programas de los partidos, pone el acento en su rol como cultura creativa ciudadana en el ámbito electoral y su alcance como barómetros de opinión, crítica política, construcción de opinión y capacidad para hacer emerger los aspectos más debatidos durante la campaña, complementando y ampliando propuestas anteriores realizadas en el escenario español (Meso-Ayerdi, Mendiguren-Galdospín y PérezDasilva, 2017).

Partimos de la hipótesis de que los memes en política deben ser reconocidos como fórmulas persuasivas en la medida en la que son estructuras creadas para construir significado (Blackmore, 1999; Foss, 2004) y contribuyen a la integración del poder visual y textual. Desde el punto de vista de la retórica visual, la pregunta de esta investigación trata de identificar en qué medida la carga persuasiva de los memes potencia los recursos o rasgos emocionales sobre otro tipo de rasgos de naturaleza racional, así como en qué grado contribuye el poder visual de la imagen a la hora de otorgar sentido al texto.

Para ello, se ha definido una investigación que, en un primer momento, incluye una reflexión inicial sobre el uso del humor en política y, especialmente, los rasgos persuasivos y de campaña política en los que se han empleado los memes como nuevo integrante y desafío de la comunicación política contemporánea (Mazzoleni y Bracciale, 2019). Tras abordar en qué consiste el poder persuasivo de dichos memes, se tomarán como referencia los principales trabajos realizados hasta el momento en el contexto internacional que han realizado aportaciones sobre el uso de los memes en los contextos políticos, tanto electorales como no electorales. Posteriormente se explica con detalle la metodología de corte cuantitativo a partir de la cual se llevó a cabo un análisis específico de los memes más populares de los debates electorales del 4 y 7 de noviembre de 2019 basado en un conjunto de indicadores de interés sobre los rasgos persuasivos más 
aceptados en la construcción del discurso de esta categoría popular y que servirán para contrastar nuestra hipótesis y preguntas de investigación.

\section{El uso del humor en política}

El vínculo entre los medios de comunicación, la comunicación política y el humor se asocia a los primeros usos de soportes informativos dirigidos al gran público (Stephens, 1988, p. 61-68) que, por ejemplo, configuró la caricatura como un nuevo modo de expresión en la segunda mitad del siglo XVIII mediante la combinación de información y arte popular para un género simbólico que aprovechaba la imaginación del lector para ejercer la crítica política (Conboy, 2004). La popularización de la prensa de masas a finales del siglo XIX institucionalizó tanto a estos géneros como a la sátira que se configuraba como una catarsis colectiva en las incipientes sociedades de masas (Chapman, 2005). Este conjunto de fórmulas ha germinado en los medios audiovisuales donde los programas o discursos que mezclan información con humor presentan mayores tasas de retención (Berg y Lippman, 2001) y de eficacia persuasiva (Lyttle, 2001). En ese sentido, se ha concluido que el humor es una manera efectiva de comunicar mensajes políticos (Niven, Lichter y Amundson, 2003).

El uso del humor en los mensajes políticos se ha manifestado, por ejemplo, como parte de la estrategia política en campaña puesto que se trata de un escenario en el que el humor puede servir para la creación y consolidación de significados compartidos que absorbe y re-significa la cultura popular (Chagas et al., 2017). Ese proceso de resignificación se sitúa, además, en la confluencia de una cultura popular tanto offline como online que ha supuesto -como señalan Mazzoleni y Bracciale- que uno de los registros de la narrativa colectiva resultante de esta interacción se defina como "humorístico-satírico, que consideramos aquí como el territorio privilegiado de la cultura pop digital del cual el meme, visto desde la perspectiva de la comunicación política, es el producto más significativo" (Mazzoleni y Bracciale, 2019, p. 50).

La emergencia del meme en la comunicación política actual ha planteado análisis comparativos entre las semejanzas estilísticas de las fórmulas clásicas con las emergentes (Ochoa, 2018) entre las que destacan la capacidad persuasiva de los memes y su rol en los diferentes escenarios que conforman la comunicación política.

\section{Los memes y su poder persuasivo}

El uso de memes se ha extendido y popularizado en los últimos años en los espacios de internet, convirtiéndose en una de las prácticas habituales de la conversación social. El fenómeno de los memes ha sido estudiado desde diferentes prismas, partiendo de las ideas conceptuales de Dawkins (1976), hasta su popularidad y desarrollo en internet (Shifman, 
2014; Shifman y Thelwall, 2009; Milner, 2013, 2015) y entendido como "a piece of culture, typically a joke, which gains influence through online transmission" (Davison, 2012).

El estudio de los memes no solo aborda su concepción como herramienta lúdica o humorística, sino, que se constituyen como nuevas formas de expresión comunicativa visual, de participación ciudadana o nueva cultura participativa (Shifman, 2014) y como entidades discursivas capaces de configurar argumentaciones (Milner, 2013), que cumplen cualidades retóricas (Ruiz Martínez, 2018).

La dimensión de los memes como formas de persuasión es relevante en la medida en que los asumimos como formas de participación activa y polifónica (Milner, 2013), como instrumentos discursivos de expresión con capacidad para articular el discurso público (Shifman, 2014) y como herramientas con capacidad para conformar e influir en los estados de ánimo, perspectivas u opiniones (Shifman, 2014; Kadir y Lokman, 2013).

Como forma de participación ciudadana, adquieren relevancia en la vida democrática, al convertirse en una expresión política e ideológica humorística (Vera, 2016), como elemento de comunicación subversiva (Huntington, 2013), y en el ámbito ideológico, al contribuir a la discusión política pública (Ruiz Martínez, 2018) o como pieza de cultura popular que funcione como herramienta de transformación de la ideología mayoritaria (Pato, 2016). Algunos autores han señalado que a la popularidad y expansión de algunos movimientos y partidos recientes como el 15M, Occupy Wall Street o Podemos, se le atribuye parte de influencia por la creación y difusión de memes propagandísticos (Milner, 2013) y su dimensión retórica (Ruiz Martínez, 2018).

Al considerar los memes como unidades discursivas, se pueden examinar desde los enfoques semiótico, discursivo y retórico (Huntington, 2013, 2016). Desde el punto de vista de la retórica visual, se combinan enfoques discursivos y semióticos y se conciben como estructuras creadas para construir significado (Dynel, 2016). En este sentido, los memes contribuyen a la integración del poder visual y textual en los contenidos online y poseen además una estructura inherente que permite que funcionen las estrategias persuasivas (Fahmy y Ibrahim, 2019). Por otra parte, los memes también presentan el riesgo del abuso de la construcción de argumentos fundados en el pathos, con menor presencia del ethos y el logos, y en detrimento de la argumentación racional (Ruiz Martínez, 2018).

\section{El uso de los memes en los contextos políticos}

Los memes online, como elementos clave de la cultura popular, desempeñan un papel importante en la creación de significado y en el reflejo de las tendencias políticas en curso (Mancera Rueda, 2020). De ahí la creciente preocupación de los investigadores por el potencial persuasivo de este nuevo género mediático en los contextos políticos (Knobel y Lankshear, 2007; Shifman y Thelwall, 2009; Davison, 2012; García-Huerta, 2014; Shifman, 2009, 2014; Chagas, 2015). 
Para algunos autores, el origen del uso de los memes en los contextos electorales debe situarse en las elecciones presidenciales americanas de 2012, unas de las primeras experiencias de fuerte visibilidad y presencia en las redes sociales de los memes (Burroughs, 2013). Si bien hay otros investigadores que identifican ya un incipiente recurso de los memes en la estrategia de campaña de 2004 y de manera algo más significativa en la de 2008 (Jenkins, 2008). Desde entonces, los estudios sobre el uso de los memes como parte de la campaña online son cada vez más numerosos y se pueden contrastar experiencias en diferentes países (Adegoju y Oyebode, 2015; Jackson y Thorsen, 2015; Romero-Cárcamo, 2015; Gal, Shifman y Kampf, 2015; Usher, 2016)

Hoy en día, los memes forman parte de los recursos habituales de las comunidades online a la hora de comentar acontecimientos de relevancia. En un contexto definido por la interrelación entre los formatos políticos y los de entretenimiento, los memes políticos online presentan bastantes similitudes, tanto por el tono, el discurso así como las herramientas empleadas. Concretamente, Márquez (2017), siguiendo un criterio funcional, llegó a identificar dos tipos de memes: aquellos que buscan un juego visual sin mayores resonancias ideológicas y los que emplean el collage fotográfico para realizar verdadera crítica política.

Todos ellos deben ser considerados verdaderos textos digitales que incluyen un discurso propio que, especialmente en los contextos políticos, presentan unos rasgos propios. Así, desde un punto de vista semiótico, los memes incluyen una "dimensión sígnica compleja" que combina varios lenguajes, y que presenta un carácter subjetivo y opinativo, puesto que plantea una visión particular de su creador o de la gente que lo difunde. Así lo observó Pérez-Salazar (2017) en su análisis de los usos sociales de los memes publicados en Facebook y Twitter durante las elecciones mexicanas.

Una de las ventajas del uso de memes online en campaña es su consideración de forma de conocimiento popular (Pestarino y Winckler, 2018), que permite ofrecer discursos paralelos para las muchas otras discusiones públicas relacionadas con el contexto electoral, además de señalar algunas de las tensiones evidentes entre las representaciones oficiales y las no oficiales. Esa fue una de las principales conclusiones a las que llegó Heiskanen (2017) en su reciente estudio sobre el uso de los memes durante la campaña presidencial de 2016 en Estados Unidos. Este trabajo incluía un análisis descriptivo de los memes más populares durante dicha campaña para concluir diciendo que la discusión de los memes de Internet generados por los usuarios, a través de la inclusión de texto superpuesto en una imagen, modificado y remezclado por los usuarios, que luego se difunde en las redes sociales y en los medios de comunicación puede considerarse una forma de participación electoral, una idea que el propio Shifman $(2009,2014)$ ya había advertido con anterioridad. La autora ilustra así las formas en las que los memes hablan de la intersección del activismo electoral y las representaciones culturales: permiten a los usuarios tomar una posición rápidamente y reaccionar al desarrollo de eventos políticos en tiempo real, brindando discursos alternativos a los principales puntos de vista de los medios, y permitiendo la 
movilización de los votantes fuera de los discursos políticos oficiales, incluido el potencial para influir en la votación.

En esa misma línea, otros investigadores han apuntado que los memes en Internet deben ser considerados una forma de expresión de los ciudadanos ante las diversas acciones de la esfera pública, "que irrumpen como un síntoma de hartazgo ciudadano y es a través de dichas prácticas creativas que los usuarios de las redes sociales digitales buscan generar un estado de opinión e intentan informar de las situaciones políticas, o de otra índole, que suceden cotidianamente" (Romero-Cárcamo, 2015).

Un reciente trabajo realizado sobre el uso de los memes publicados en Twitter en un contexto electoral como fue la jornada electoral del 26] en España lo realizaron MesoAyerdi, Mendiguren-Galdospín y Pérez-Dasilva (2017). Estos autores analizaron la popularidad de los memes en los contextos políticos como contenido alternativo a través de los cuales los usuarios manifiestan su sentir, generalmente, haciendo uso del humor y de la sátira. Para ello, realizaron un estudio descriptivo-interpretativo, en el que combinaron la metodología del análisis del discurso con la del análisis de contenido de memes. Los autores llegaron a la conclusión de que los memes se emplearon para comunicar ideas y generar un estado de opinión. Irrumpieron en la jornada electoral como un síntoma tanto de hartazgo ciudadano como de desconfianza y decepción hacia sus líderes políticos. Ahora bien, no se confirmó la previsión de que los contenidos sean más lacerantes con el partido en el poder y con el principal partido en la oposición. El trabajo demostró también que los momentos de más actividad creativa coincidían con los hechos más destacados del 26J.

Precisamente dentro de cualquier carrera electoral, uno de los acontecimientos clave son sin duda los debates electorales, que se convierten también en momentos propicios para la proliferación de memes en las comunidades online. Uno de los trabajos más destacados sobre el uso de los memes difundidos a raíz de los debates electorales es el de Chagas et al. (2017). Estos autores tomaron como muestra las elecciones de Brasil de 2014 (bautizadas como las "elecciones de los memes") con el fin de ofrecer una taxonomía útil y objetiva para identificar los tipos de memes, así como conocer qué tipos de contenidos de los memes alcanzaron mayor repercusión y propagación. El modelo que proponen, que toma como base otras propuestas taxonómicas anteriores (Shifman, 2014; Tay, 2012), parte de una muestra de 6.000 imágenes, que fueron analizadas a partir de 175 variables binarias. Su taxonomía para analizar los tipos de memes políticos durante los debates electorales se divide en tres grandes macrocategorías -memes políticos persuasivos, de acción popular y de discusión pública- con 4 microcategorías cada una. Los resultados demostraron que la mayoría de los memes difundidos se corresponden con la macrocategoría de discusión pública y memes de acción popular.

Sobre esas mismas elecciones de 2014 en Brasil, Dalmonte, Ferreira y Cardoso (2016) quisieron comprobar las formas de interacción de los sujetos en los procesos de discusión política a raíz del uso de los memes en los debates electorales. Su objetivo fue 
verificar el crecimiento de la participación política de la audiencia, así como las formas en las que estos contenidos se utilizan. Llegaron a la conclusión de que, mediante estos nuevos modelos de consumo, la audiencia asume un rol más activo y un papel más relevante en la apropiación y resignificación de los mensajes, participando en la apropiación y circulación de contenidos en detrimento de una posición de audiencia objetiva y pasiva.

Los memes online, utilizados en contextos electorales, también pueden servir para repensar la conexión entre el compromiso cívico y la acción política desde la perspectiva de la participación casual del ciudadano con la política en Internet. Sirva de ejemplo la reflexión sobre la relación entre el compromiso político, la conversación informal y la acción colectiva a través del juego político que representó el uso de los memes difundidos en Twitter durante el debate electoral de 2014 en Portugal (Chagas et al., 2017). Para ello, los autores utilizaron como muestra fotografías sacadas directamente de la televisión durante el debate caracterizadas como una acción colectiva basada en una conversación informal e identificaron la posición política predominante en cada caso.

En definitiva, el estudio de los memes políticos permite identificar las formas de pensar, los comportamientos y las acciones, tanto del partido político que los envía como de la comunidad online, que es, al fin y al cabo, quien les atribuye valor (Knobel y Lankshear, 2007). A la luz de esta idea, cabe destacar uno de los escasos trabajos específicos sobre el uso de memes en debates en España realizado por Martínez-Rolán y Piñeiro-Otero (2016) y que sirve como referencia para la presente investigación. Estos autores analizaron el uso estratégico de las imágenes en el discurso digital de los partidos políticos españoles en Twitter en el debate del estado de la nación en 2015. Si bien, no se trata de un debate electoral al uso, el análisis de contenido realizado por estos autores incluyó un etiquetado temático de memes mediante el análisis de significados (imagen y texto). Su estudio demuestra cómo el potencial memético de algunos perfiles políticos para generar un impacto y suscitar mayor engagement entre sus seguidores se basa en el tamaño de su comunidad online, pero, sobre todo en un mayor compromiso de estos seguidores con un líder de partido específico (Ballesteros-Herencia, 2020). Además, los autores observaron una cierta polarización política online, considerando dos claras tendencias en la construcción estratégica de los memes: por un lado, para fortalecer las ideas a favor de un líder propio y, por otro, para criticar la labor de otros partidos, especialmente, la gestión gubernamental.

\section{Metodología: selección de la muestra y codificación}

La muestra se obtuvo a través de varios procesos. En primer lugar, se obtuvieron las publicaciones de Twitter que emplearon cualquiera de los hashtags relacionados con el debate a través de un software que se suele emplear para monitorizar los discursos de marcas en redes sociales. Los hashtags de búsqueda inicial fueron los oficiales: "\#ÚltimaOportunidadL6", "\#DebateElectoral", "\#DebateARV", "\#debatea5RTVE", 
"\#EIDebate4N", que se ampliaron con aquellos hashtags que aparecían en las publicaciones y que se incorporaron a la base de datos de búsquedas. Los resultados de estos nuevos hashtags no fueron apreciables en su mayoría ya que, habitualmente, responden a chascarrillos que se producían a lo largo del debate como, por ejemplo, \#Aúnhuelealeche, \#Miraesteadoquin o \#Mamadas. El número de hashtags fue muy elevado aunque la muestra se concentró en torno a los oficiales. El proceso de recogida se sistematizó empleando una conexión a la API de Twitter (Interfaz de Programación de Aplicaciones) a través del software $\mathrm{R}$ y su librería Rtweet.

Estos datos se refinaron en diferentes intervalos para cada debate con el objetivo de identificar posibles variaciones en la interacción (likes y retuits) como posibles desapariciones de contenido. Se obtuvieron, aproximadamente, unos 500 tuits significativos de cada uno de los debates (en número de retuits, likes o perfil del autor) de los que se discriminaron todos aquellos que no eran memes y que respondían a otro tipo de sentido (informativo, polémico, opinativo etc.).

No existe un criterio unificado en el caso de muestras tan concretas porque otras investigaciones suelen realizar un número de corte con relación al número de retuits (Reichart, Pegoraro y Cruikshank, 2019). Teniendo en cuenta esta situación, se valoraron diferentes fórmulas para intentar medir la influencia tangible (aquella que recibía una interacción) y no tangible (aquella en la que el tuit es leído pero que no recibe interacción dentro de la red social) de los tuits como conjunto. Se tuvieron en cuenta investigaciones recientes que tratan de matizar el valor del retuit como único indicador de influencia (Lu y Luqiu, 2019). Por ello, a partir de las referencias anteriores, se optó por un "índice de influencia", que permitiera jerarquizar el alcance de cada uno de los tuits. Dicho índice de influencia se construyó a partir de estimaciones anteriores (Alperin, Gómez y Haustein, 2019) y la interpretación, desde el punto de vista de la investigación, del nivel de compromiso implícito en un retuit, un like o el número de followers de la fuente original (Firdaus, Ding y Sadeghian, 2019; Pond y Lewis, 2019). De esta forma, la estimación se calculó a partir de la suma del número de retuits, el número de likes dividido por 3 y el número de followers de la fuente dividido por mil.

Tras realizar una serie de cálculos con el total de la muestra vinculada a los tuits que contenían algún tipo de meme, se estableció una muestra en la que se incluyeron todos los tuits con un índice de influencia superior a 100 en el caso del debate del 4 de noviembre de 2019 y superior a 50 en el caso del debate del 7 de noviembre de 2019. Las diferencias de valor en dicho índice responden a un factor corrector con relación al total de la muestra que, en el primer caso, era mucho más numerosa.

La muestra final comprendió 39 tuits para el debate del $4 \mathrm{~N}$ y 23 para el debate del $7 \mathrm{~N}$. Un corte que se consideró representativo - desde el punto de vista mediático- teniendo en cuenta el índice de influencia total de la muestra frente al correspondiente al total del universo (en otras palabras, los que hay son muy representativos porque engloban, aproximadamente, el $98 \%$ de retuits y el $95 \%$ de likes del total). Siguiendo los patrones 
de la estadística descriptiva, este análisis podría considerarse un patrón para modelos de carácter inferencial y con muestras superiores.

La unidad de análisis natural fue cada uno de los tuits seleccionados a los que se aplicó una ficha de codificación que recogía tanto datos formales de los mismos como 9 variables relacionadas con su construcción. Con el fin de analizar la dimensión temática de los memes, se utilizó la clasificación propuesta por Bebić y Volarevic (2018). Estos autores distinguieron entre temas nacionales de naturaleza social (domestic social issues), temas nacionales de naturaleza política (domestic political issues), temas internacionales de naturaleza social (foreign social issues) y temas internacionales de naturaleza política (foreign political issues).

Para analizar los tipos de imágenes que se incluyen en cada meme, nos basamos en el trabajo de Martínez-Rolán y Piñeiro-Otero (2016) sobre el uso de imágenes en el discurso digital de los partidos políticos españoles en Twitter, durante el debate del estado de la nación de 2015 en España. A partir de las aportaciones de estos autores se diferenció una tipología de los memes gráficos que incluía fotos tomada de capturas de televisión (screen prints), composiciones de más de una foto (photo collages), fotos (single photos), gráficos (graphics), composiciones de texto e imágenes muy estereotipadas (macro images), infográficos (infographics), tablas (tables) y texto visualizado sin imágenes (visual text).

Para realizar la taxonomía de los memes en el contexto de los debates electorales nos basamos en el trabajo de Chagas et al. (2017), quienes realizaron un análisis de contenido cuantitativo de memes recogidos durante los diferentes debates TV presidenciales de Brasil en 2014 en Twitter. Su taxonomía se divide en 3 grandes macrocategorías (basadas en el trabajo de Shifman, 2014) con 4 microcategorías cada una. Así, distinguen entre memes políticos persuasivos -o aquellos estratégicamente diseñados para ser difundidos y / o buscan apoyo para una candidatura particular con la intención de convencer al votante - que se subdividen en aquellos de retórica proposicional o apelación pragmática, retórica seductora o apelación emocional, retórica ético-moral o apelación ideológica, retórica crítica o apelación de la credibilidad de la fuente; por otra parte, memes de acción popular -caracterizados por ser una construcción colectiva de significado, movilizando al ciudadano común- subdivididos en acción colectiva, acción colectiva híbrida, acción conectiva, acción conectiva de compromiso relativo; y, finalmente, aquellos memes de discusión pública -aquellos diseñados para funcionar como comentarios irracionales de los votantes sobre una situación o reacción específica, a menudo identificada como bromas-, que a su vez se subdividen en lugares comunes de la política, alusiones literarias o culturales, chistes sobre personajes políticos, chistes sobre situaciones.

El proceso de codificación fue realizado por los autores de la investigación a través de una ronda de análisis de una muestra común en la que se aseguró la fiabilidad del estudio analizando una muestra común de 10 tuits de cada una de las series. Tras dos 
rondas de codificación se obtuvo un nivel de acuerdo entre codificadores del $91,3 \%$. Posteriormente, se utilizó el programa informático SPSS versión 20 para proceder al análisis estadístico de las frecuencias, así como la elaboración de tablas de contingencia. Una vez obtenidos los resultados, se procedió a comparar los resultados obtenidos de manera global, así como diferenciados según cada uno de los dos debates analizados.

\section{Resultados}

Después de la codificación de todos los tuits seleccionados, se procedió a la evaluación de las intervenciones recogidas a través de los indicadores de su construcción (Bebić y Volarevic, 2018; Martínez-Rolán y Piñeiro-Otero, 2016; Chagas et al., 2017). A continuación, se procedió con la explotación de los datos y con la elaboración de tablas de contingencia con frecuencias simples utilizando el programa SPSS 20. Los resultados de ambos debates que se muestran a continuación están referidos al total de las intervenciones de cada uno de los debates.

El uso de la imagen en la conversación social en torno a los debates políticos

El análisis de la conversación social en torno a \#DebateElectoral del $4 \mathrm{~N}$ y el $7 \mathrm{~N}$ se concentró en los hashtags oficiales (\#ÚltimaOportunidadL6, \#DebateElectoral, \#DebateARV", \#debatea5RTVE, \#EIDebate4N, \#\#EIDebate7N) y nos ha permitido señalar diferentes elementos comunes y divergentes entre los memes analizados.

En lo que se refiere al tipo de imágenes utilizadas durante la conversación social en forma de meme, destaca el uso de capturas de pantalla de televisión en el 37,9\% del total, seguido de la elaboración de composiciones visuales o foto collages (19\%) y la incorporación gifs $(17,2 \%)$ y fotos $(15,5 \%)$. Si nos fijamos en posibles diferencias en función de cada uno de los debates, el uso de capturas de pantalla de televisión fue sustancialmente más elevado el $4 \mathrm{~N}(51,4 \%)$ que el $7 \mathrm{~N}(14,3 \%)$. En este último debate las prácticas más repetidas fueron la incorporación de fotos $(23,8 \%)$ y composiciones visuales $(23,8 \%)$. En cuanto al uso de videos o gifs, se detectaron valores similares en ambos debates, con un $16,2 \%$ de las imágenes del debate del $4 \mathrm{~N}$ y $19 \%$ del debate del $7 \mathrm{~N}$. Solo el $1,7 \%$, del total de las unidades analizadas en ambos debates no contenía ningún tipo de imagen.

Por lo que se refiere a la construcción elemental de los mensajes, tal y como muestra el Gráfico 1, en más de la mitad de los casos $(55,2 \%)$ la imagen domina sobre el texto. Una primacía que se traduce en dos tendencias: el uso de imágenes sin texto en el tuit o el empleo de un texto breve, de carácter residual, que no tenía influencia en la imagen (donde reposaba la fuerza del discurso). Por otro lado, la dominancia de texto e imagen por igual se manifiesta en el $27,6 \%$ de la muestra. La predominancia textual en los memes es apenas residual, con tan sólo un 17,2\% de los casos. Esta clara apuesta por 
la imagen a la hora de construir los memes en redes sociales se mantuvo en cada uno de los debates, aunque con ciertas diferencias. Mientras que, en la conversación analizada en torno al $4 \mathrm{~N}$, el $67,6 \%$ de los tuits muestran dominancia del elemento visual frente al textual $(13,5 \%)$, los memes en torno al debate referido al $7 \mathrm{~N}$ se caracterizaron por otorgar un protagonismo igualitario entre los elementos visuales y textuales $(42,9 \%)$, de tal modo que la imagen aparecía como dominadora sobre el texto en menos ocasiones (33,3\% frente $23,8 \%$ ). Con todo, si bien no figura en el Gráfico 1 , la consistencia visual y textual de los tuits fue evidente en ambos casos, considerando el dato de que el texto se mostró como elemento complementario a la imagen en el $62,1 \%$ del total de los mensajes analizados, con valores del $48,6 \%$ en el caso del $4 \mathrm{~N}$ y del $85,7 \%$ en el $7 \mathrm{~N}$.

\section{Gráfico 1 \\ Elemento dominante (texto versus imagen) (\%)}

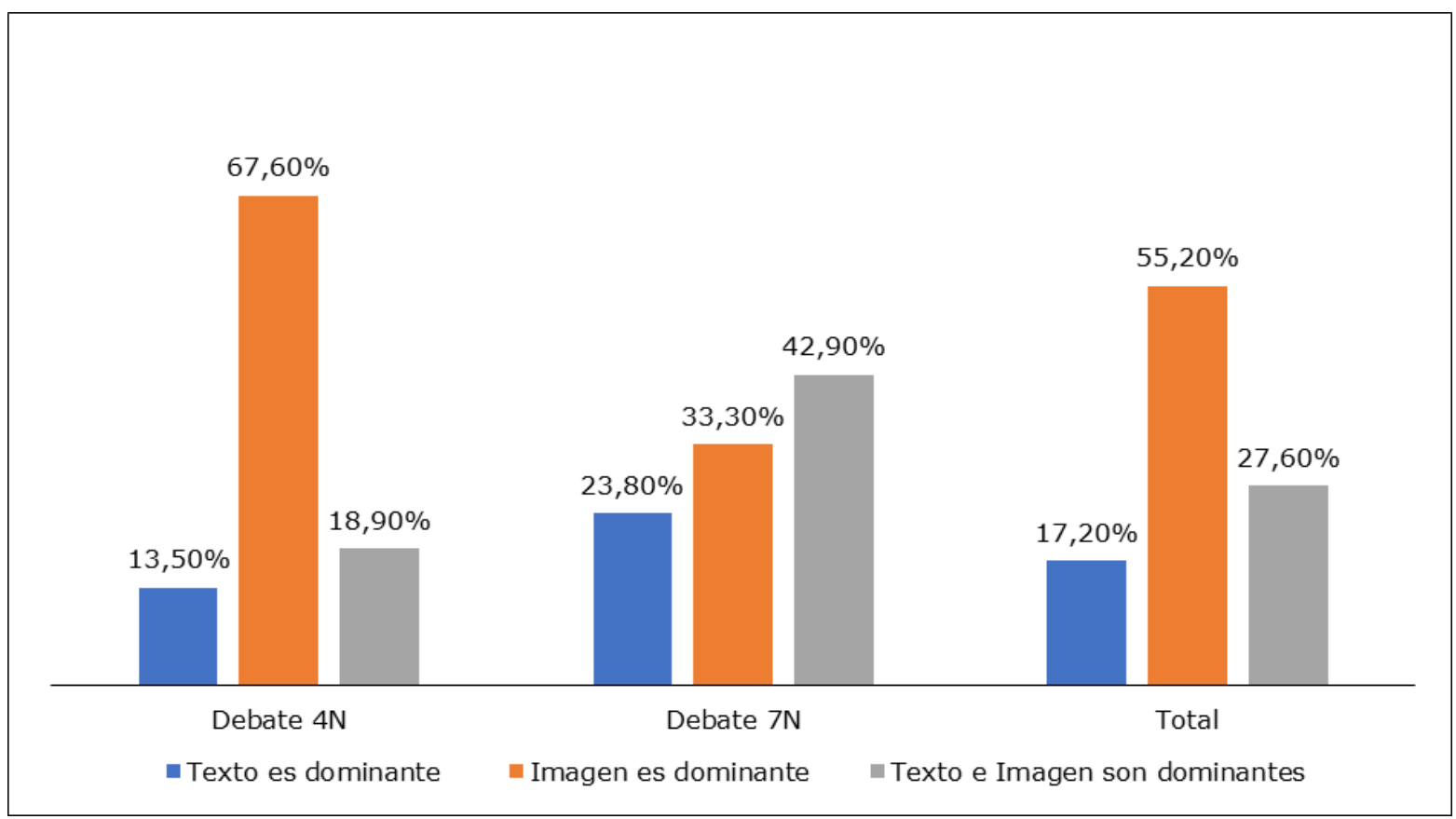

Fuente: Elaboración propia.

Método de extracción: análisis de frecuencias.

Discurso y persuasión en la conversación social en torno a los debates políticos

El análisis en torno a los debates electorales del 4N y el 7N arroja diferentes resultados sobre la construcción discursiva de la conversación social en Twitter previa a la cita electoral (Gráfico 2). Partiendo del núcleo discursivo, nos fijamos en los temas referenciados en cada uno de los memes analizados. De este modo, observamos cómo en 
el $66,7 \%$ del total de los casos la conversación giró en torno a temas nacionales de naturaleza política ("domestic political issue", Bebić y Volarevic, 2018), que necesariamente incluye menciones expresas en el mensaje a la campaña electoral, el voto, las encuestas o diversas menciones a políticos o partidos políticos. En ambos debates los valores resultaron similares $(75,7 \%$ de los mensajes de los debates en el $4 \mathrm{~N}$ y $72,4 \%$ en el $7 \mathrm{~N}$ ) con la conversación centrada mayoritariamente en temas de naturaleza política nacional; seguida de temas de naturaleza social nacional $(24,3 \%$ de los casos en el $4 \mathrm{~N}$ y el $27,6 \%$ en el debate del $7 N$ ).

\section{Gráfico 2}

Núcleo discursivo

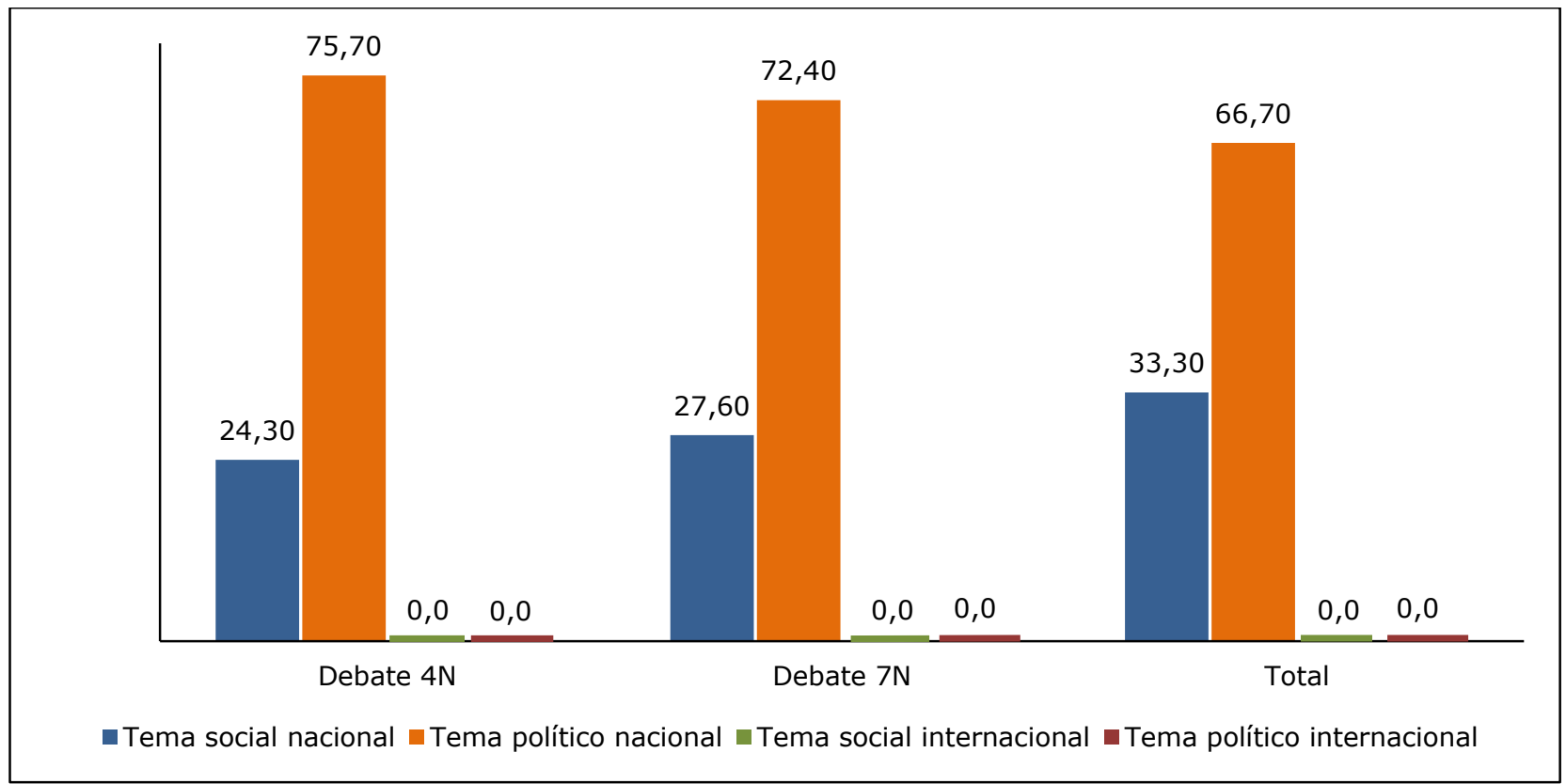

Fuente: Elaboración propia.

Método de extracción: análisis de frecuencias.

Siguiendo la propuesta de categorías de Chagas et al. (2017) para identificar los tipos de memes, se llevó a cabo un análisis taxonómico de la conversación social en torno a los dos debates televisivos analizados en este estudio. Los resultados totales muestran una predominancia de los tuits de humor en la categoría de discusión pública. Así, tal y como muestra el Gráfico 3, existió un claro predominio de los memes de categoría de discusión pública con chistes sobre personajes políticos $(39,7 \%)$ y la discusión pública con chistes sobre situaciones (19\%), seguidos de los memes de discusión pública con alusiones culturales y literarias $(17,2 \%)$. 
Gráfico 3

Taxonomía de memes (\%)

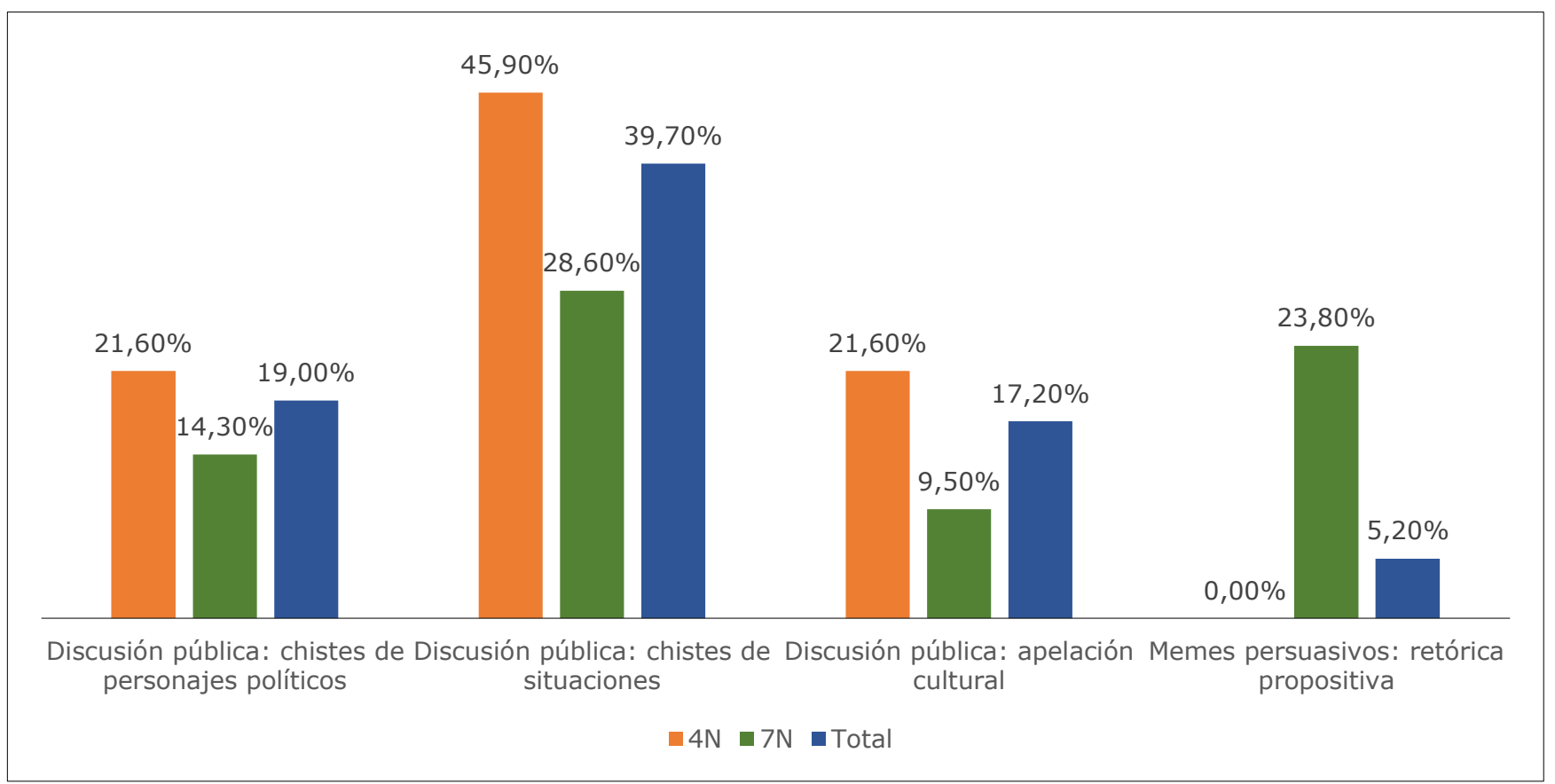

Fuente: Elaboración propia.

Método de extracción: análisis de frecuencias.

Atendiendo a las diferencias entre cada uno de los debates, los chistes sobre situaciones, es decir, aquellos que incluyen comentarios sobre reacciones, expresiones faciales, gestuales o corporales de los candidatos en ciertas situaciones, predominaron en la conversación en torno al debate del $4 \mathrm{~N}(45,9 \%)$; seguido de otras categorías de discusión pública como los chistes sobre personajes políticos $(21,6 \%)$ y las alusiones culturales o literarias $(21,6 \%)$. En cuanto a la conversación en torno al debate del $7 \mathrm{~N}$, los porcentajes presentaron menos desequilibrios, de tal modo que aquí la discusión pública fue la categoría más frecuente $y$, dentro de ella, los chistes sobre situaciones $(28,6 \%)$, seguidos de la categoría de memes persuasivos con retórica propositiva o apelación pragmática $(23,8 \%)$ que hacían referencia a las propuestas del candidato, o bien planteaban una discusión que apunta al cálculo racional del votante o abarcaban temas discutidos en las elecciones y las opiniones de los candidatos (Chagas et al., 2017). 


\section{Imagen 1 \\ Uso de memes con alusiones culturales o literarias}
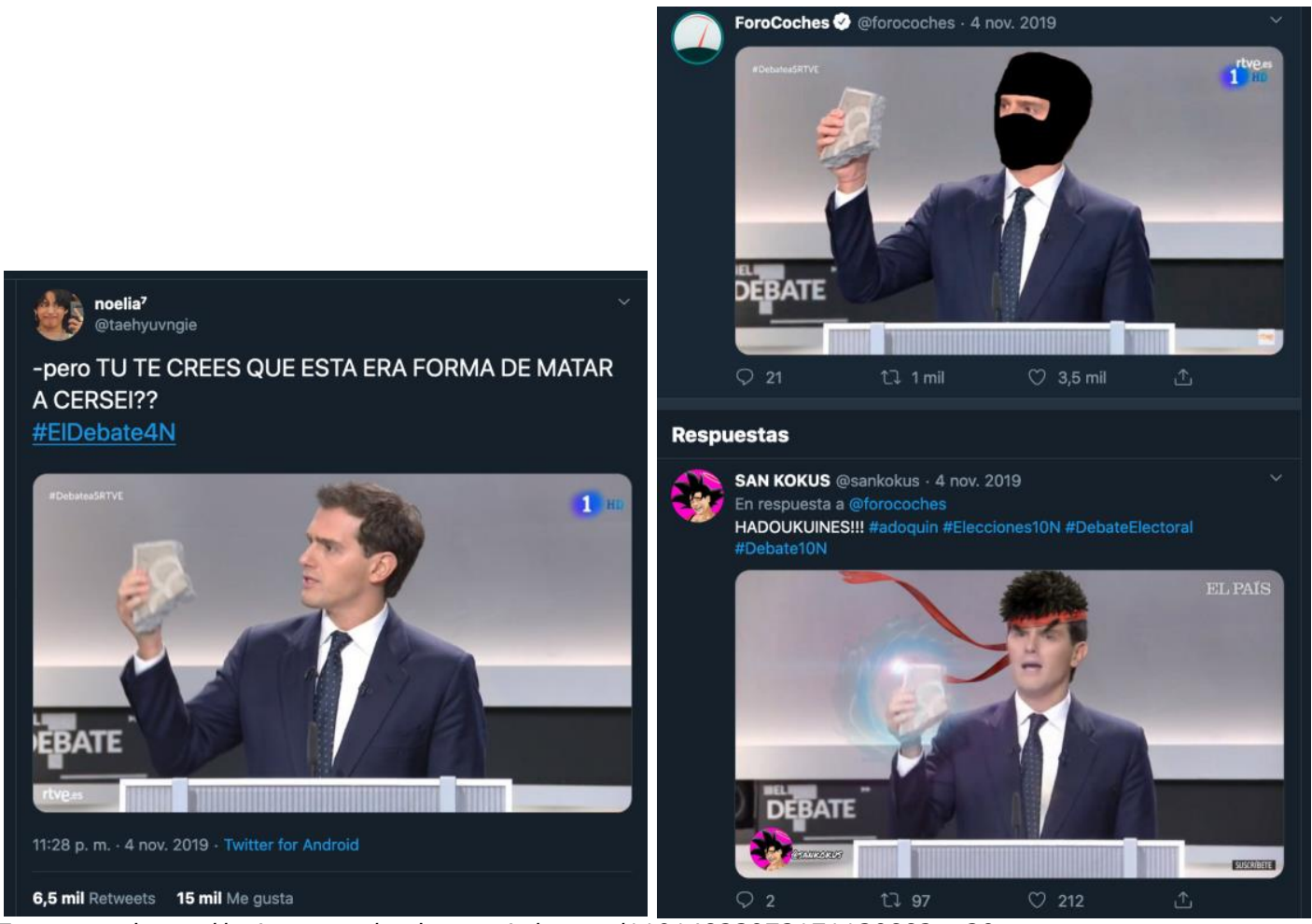

Fuente: <https://twitter.com/taehyuvngie/status/1191482307217113088?s=20> y

<https://twitter.com/forocoches/status/1191469888528883712?s=20>. Consultado el: 15 mar. 2020.

En cuanto a la dimensión retórica de la conversación social estudiada, se ha tenido en cuenta la fase discursiva inventio, a través del análisis de la presencia de los elementos aristotélicos de la persuasión: ethos, logos y pathos. Los resultados totales indican que la argumentación afectiva o emocional es el tipo argumentativo más repetido, con una presencia del pathos del 62,1\%, seguido de la argumentación ético-moral basada en los rasgos del orador, indicada en el ethos con un 17,2\% y, finalmente, la argumentación racional a través de una frecuencia de $13,8 \%$ en los indicadores del logos (Gráfico 4). En el caso de cada uno de los debates se visibiliza indistintamente el claro protagonismo del discurso emocional a través de pathos ( $64,9 \%$ en el discurso del $4 \mathrm{~N}$ y $57,1 \%$ en el debate del $7 N)$. 


\section{Gráfico 4}

Técnica persuasiva dominante en los memes

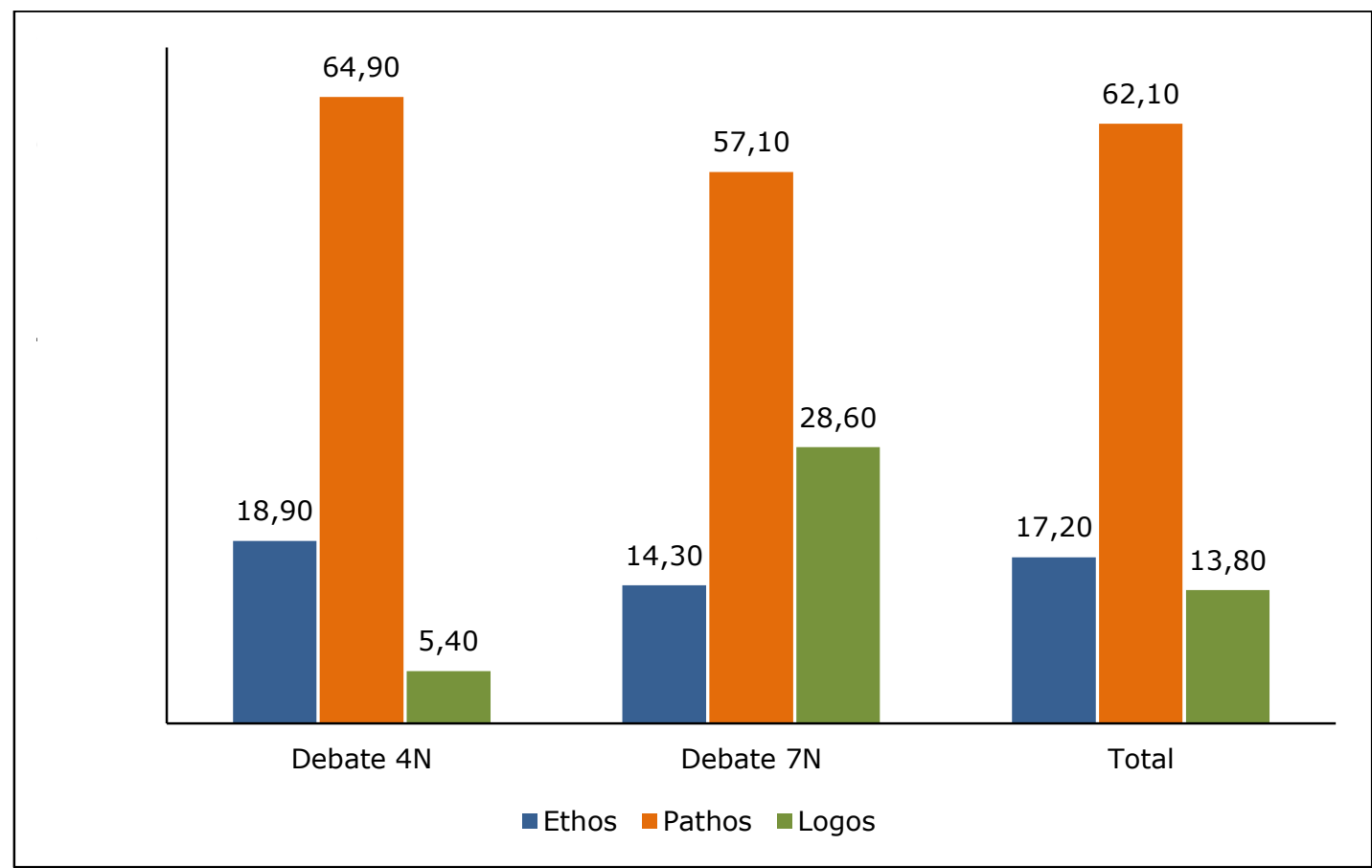

Fuente: Elaboración propia.

Método de extracción: análisis de frecuencias.

De manera específica, dentro del pathos, el recurso retórico más utilizado para la expresión de afectos y emociones con finalidad persuasiva ha sido el humor y el sarcasmo, con una frecuencia de $97,3 \%$ en la conversación en torno al debate del $4 \mathrm{~N} ; 76,2 \%$ en los casos analizados en torno al debate del $7 \mathrm{~N}$, que supone el $89,7 \%$ en los resultados totales. 
Imagen 2

Meme de discusión pública con alusión cultural

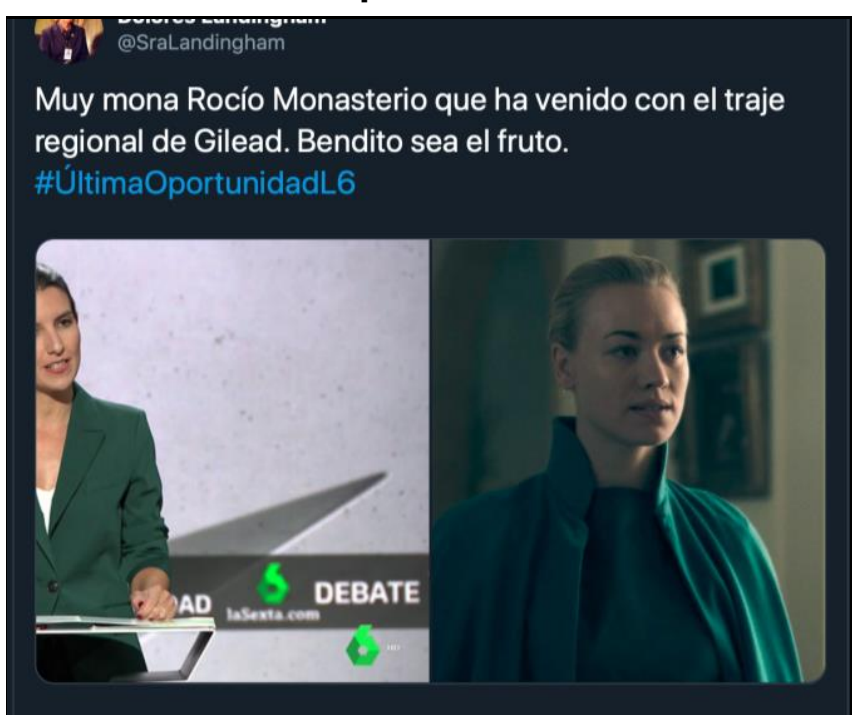

Fuente:<https://twitter.com/SraLandingham/status/1192550 $665815568388 ? \mathrm{~s}=20>$. Consultado el: 15 feb. 2020 .

En relación al elemento dominante en los diferentes memes, se realizaron diferentes tablas de contingencia para identificar posibles relaciones entre las variables clave de nuestro estudio. En este sentido, cabe reseñar, que únicamente se encontró una asociación estadísticamente significativa (Chi-square $\mathbf{5 . 0 0 1 )}$ entre el tipo de imagen y el elemento dominante en cada meme. Si bien la presencia del pathos fue prácticamente generalizable en todos los casos, se detectó una presencia significativamente mayor de este elemento persuasivo en las imágenes que habían sido tomadas como capturas de pantalla $(81,8 \%$ del total) que en otros casos, tales como las fotos $(66,7 \%)$, el montaje de fotografías o collage $(45,5 \%)$ o incluso los videos $(50 \%)$. Este dato deja clara la importancia cada vez mayor que aquieren las imágenes difundidas a través de los medios como recurso simbólico humorístico por parte de la audiencia para expresar estados emocionales de una forma accesible en el transcurso de la conversación social paralela al desarrollo de estos debates electorales. 
Tabla 1

Relación entre el tipo de imagen y el recurso persuasivo utilizado

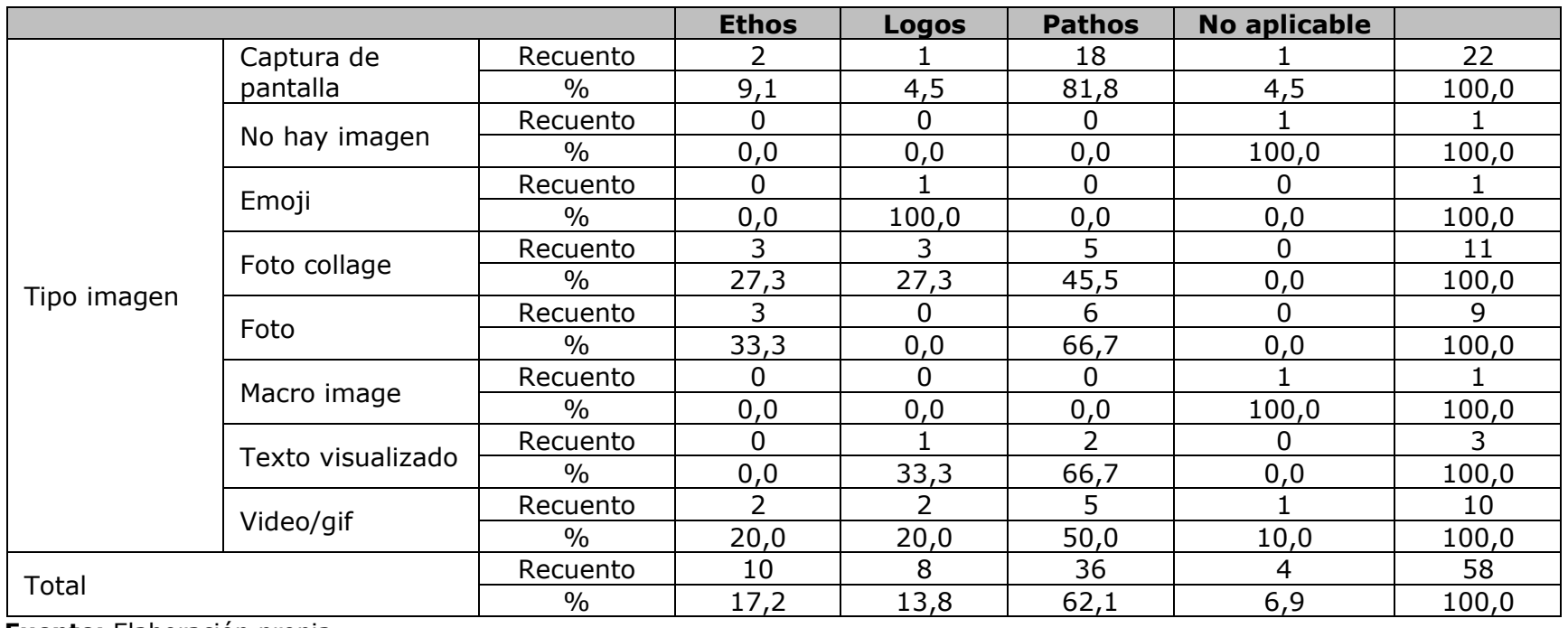

Fuente: Elaboración propia.

Método de extracción: análisis de frecuencias.

La viralidad de los memes sobre los debates políticos en función de los recursos retóricos

Con el fin de comprobar la relación entre el uso de los diferentes elementos retóricos y su capacidad para obtener mayor o menor viralidad se procedió a diferenciar el total de la muestra de memes a partir de su nivel de retuits que caracterizaba a cada unidad de análisis. De este modo, se agruparon los memes en torno a 3 grupos de retuits que se ordenaron en función de los valores medios de la muestra: nivel alto, nivel medio y nivel bajo.

Concretamente, los resultados demostraron una asociación estadísticamente significativa mediante tablas de contingencia (Chi-square $\leq .005$ ) entre el nivel de retuits y el elemento retórico dominante en los memes (ethos, logos o pathos), en el sentido de que aquellos memes que utilizaron mayoritariamente el pathos como recurso persuasivo fueron también los que presentaban mayor número de retuits. Por contraste, los memes que optaron por utilizar el logos como recurso persuasivo resultaron menos atractivos y su capacidad de producir viralidad fue menor. 
Tabla 2

Relación entre el nivel de retuits y el recurso persuasivo utilizado (\%)

\begin{tabular}{|l|c|c|c|c|}
\hline & Retuit bajo & Retuit medio & Retuit alto & Total \\
\hline Ethos & 30 & 70 & 0 & 100 \\
\hline Logos & 50 & 12,50 & 37,50 & 100 \\
\hline Pathos & 27,80 & 19,40 & 52,80 & 100 \\
\hline No aplicable & 75 & 25 & 0 & 100 \\
\hline
\end{tabular}

Fuente: Elaboración propia.

Método de extracción: tabla de contingencia.

Sirva de ejemplo para ilustrar la capacidad viral de los memes analizados la selección de aquellos que obtuvieron mayor número de retuits en cada uno de los dos debates. Así, tal y como se aprecia en la Imagen 1, en el debate del $4 \mathrm{~N}$, el meme más viralizado fue con una imagen captada de la televisión en la que figuraba el líder de Ciudadanos, Albert Rivera, en el momento en el que éste sacó una piedra para ilustrar una de sus intervenciones. La comunidad virtual utilizó esta imagen para añadir y modificar el significado de la misma en un tono humorístico, añadiéndole diferentes elementos y comentarios. Los dos memes más compartidos (Imagen 3) estaban vinculados a este candidato y alcanzaron 26.300 y 24.000 respectivamente.

\section{Imagen 3}

Meme más viralizado en el debate del $4 \mathbf{N}$
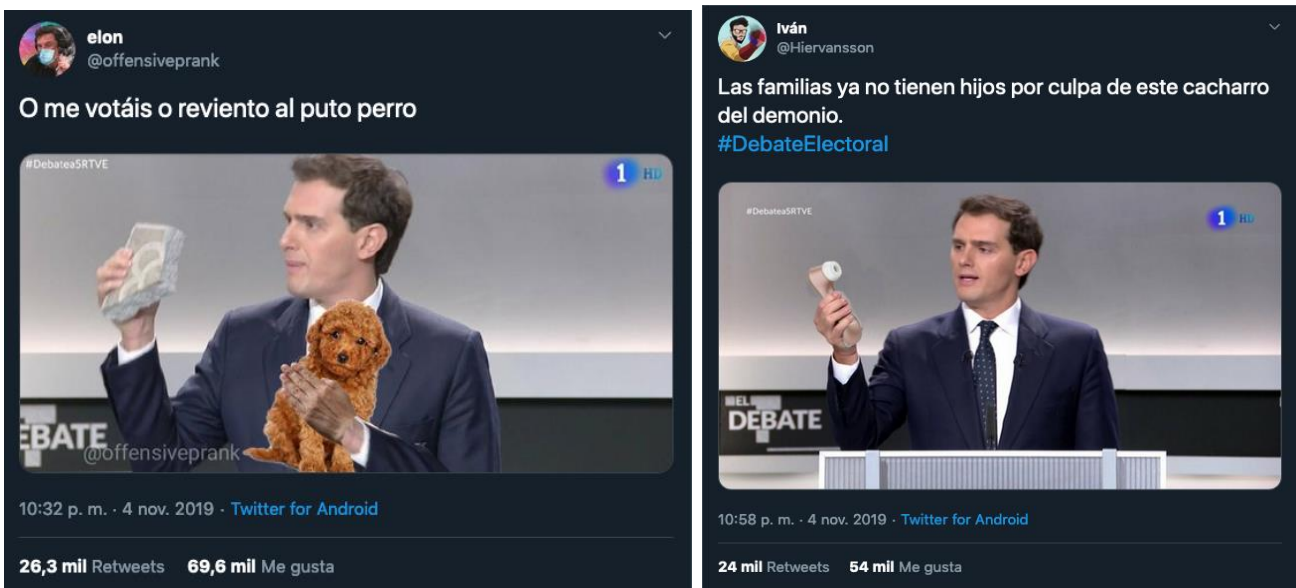

Fuente: <https://twitter.com/offensiveprank/status/1191468334417686528> y <https://twitter.com/Hiervansson/status/1191474763379675138>. Consultado el: 15 feb. 2020.

En el caso del debate del $7 \mathrm{~N}$, curiosamente, el meme que resultó ser más viral no contaba con ninguna imagen, sino que simplemente añadía un texto en el que se evidenciaban las diferencias entre dos de las candidatas, Irene Montero y Rocío Monasterio, 
también en un tono jocoso, como se aprecia en la Imagen 4. En este caso, el meme consiguió un total de 4.000 retuits.

\section{Imagen 4}

Meme más viralizado en el debate del $7 \mathbf{N}$

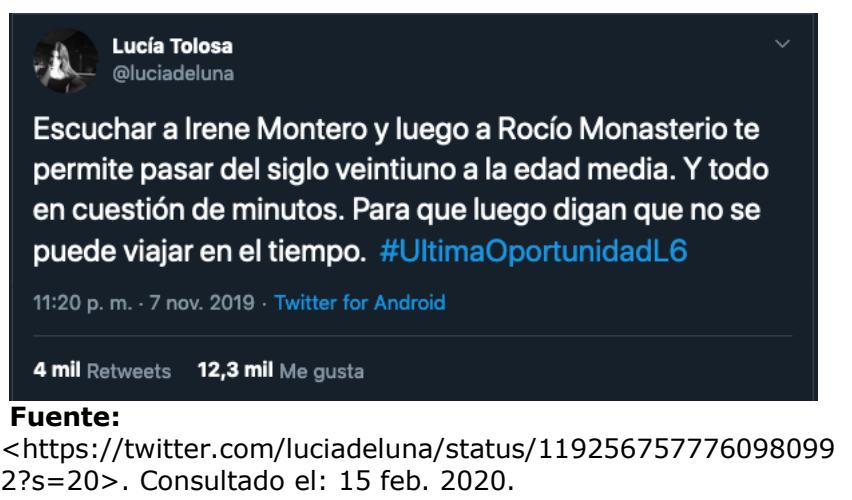

\section{Consideraciones finales}

La aportación de los memes en el ámbito de la representación simbólica de los principales debates electorales de las elecciones españolas de noviembre de 2019 en las redes sociales consolida su definición como un género, a medio camino entre lo humorístico, lo informativo y lo político, con una amplia aceptación social para la manifestación tanto de juegos visuales o de ingenio como de la crítica política (Márquez, 2017). Este artículo fortalece, así, el corpus de investigaciones que subrayan la concepción del meme online, no sólo como herramienta lúdica o humorística, sino que, además, se constituye como una nueva forma de expresión comunicativa visual, de participación ciudadana o nueva cultura participativa (Shifman, 2014) y como una entidade discursiva capaz de configurar argumentaciones (Milner, 2013) que cumplen cualidades retóricas (Ruiz Martínez, 2018). En los contextos políticos, son empleadas como unidades discursivas persuasivas que buscan comunicar ideas y opiniones y contribuyen a la comunicación subversiva y representativa y a la influencia sobre los estados de opinión, y nos permiten aproximarnos a las opiniones y posturas respecto a los líderes políticos sobre los que enuncian (Martínez-Rolán y Piñeiro-Otero, 2016).

Tal y como ha demostrado este artículo, la dimensión de los memes como formas de persuasión política es relevante en la medida en que los asumimos como formas de participación activa y polifónica (Milner, 2013) que contribuyen a la integración del poder visual y textual en los contenidos online y poseen además una estructura inherente que permite que funcionen las estrategias persuasivas (Fahmy e Ibrahim, 2019).

Atendiendo a los resultados de esta investigación sobre el uso de los memes en la conversación social en torno a los debates electorales del $4 \mathrm{~N}$ y el $7 \mathrm{~N}$, se constata que, en 
la línea de nuestra hipótesis de investigación, en el meme predomina una naturaleza visual frente a la textual que, además, se traduce en una carga persuasiva que apela claramente a los rasgos emocionales.

Además, en lo que se refiere a la relación entre discurso y persuasión en la conversación social en torno a los debates políticos, los resultados obtenidos permiten afirmar que la argumentación afectiva o emocional es el tipo argumentativo más repetido en los memes políticos online, con una considerable presencia del pathos, seguida de la argumentación ético-moral y basada en los rasgos del orador, indicada en el ethos, y en menor medida, de la argumentación racional, a través del logos.

Esa clara apuesta por los recursos persuasivos basados en el componente emocional -especialmente el humor y el sarcasmo-, a tenor de nuestros resultados, conlleva asimismo una mayor dósis de viralidad entre la comunidad online. Por lo que, respecto a la cuestión de la viralidad de los memes sobre los debates políticos en función de los recursos retóricos, nuestro estudio destaca la importancia del componente emocional como elemento clave para su difusión.

En ese sentido, los temas que aparecieron en los memes de ambos discursos privilegiaron las intervenciones más excentricas o aquellas que se percibían como extremos desde el punto de vista ideológico. No se trataba, en ambos casos, de los partidos hegemónicos que, además, obtuvieron los mejores resultados electorales. Los propios memes derivaron a una construcción doméstica de la política que resulta lógica en el ámbito en que se situaban los propios debates.

La muestra analizada presenta la recurrencia de motivos, con leves variaciones, que constituyen los nuevos rasgos visuales de una retórica política popular a través de este medio que, en futuras investigaciones, convendría concretar, sobre todo la consistencia tanto visual como textual. Por último, como limitación del estudio, no se han obtenido datos concluyentes sobre la relación entre los creadores de los tuits, el uso de hashtags o la popularidad del discurso. Una serie de cruces que resulta de interés y que convendrá precisar en el futuro.

\section{Referencias bibliográficas}

Adegoju, A.; OYEBODE, O. "Humour as discursive practice in Nigeria's 2015 presidential election online campaign discourse". Discourse Studies, USA, vol. 17, no 6, p. 643-662, 2015.

AlPERIN, J. P.; Gómez, C. J.; HAUSTEIN, S. "Identifying diffusion patterns of research articles on Twitter: a case study of online engagement with open access articles". Public Understanding of Science, USA, vol. 28, no 1, p. 2-18, 2019.

Ballesteros-Herencia, C. "Los marcos del compromiso: framing y engagement digital en la campaña electoral de España de 2015". Observatorio (OBS*) Journal, vol. 14, no 3, p. 98-119, 2020.

BARNARD, S. R. "'Tweet or be sacked': Twitter and the new elements of journalistic practice". Journalism, USA, vol. 17, p. 190-207, 2016. 
BeBiĆ, D.; VolAREVIC, M. "Do not mess with a meme: the use of viral content in communicating politics". Communication \& Society, España, vol. 31, n³, p. 43-56, 2018.

BERG, E.; LIPPMAN, L. "Does humor in radio advertising affect recognition of novel product brand names?". Journal of General Psychology, USA, n 128, p. 194-205, 2001.

BLACKMORE, S. The meme machine. Oxford: Oxford University Press, 1999.

BURROUGHS, B. "FCJ-165 Obama trolling: memes, salutes and an agonistic politics in the 2012 presidential election". The Fibreculture Journal, Australia, no 165, p. 258-277, 2013.

CHAGAS, V. "Entre criadores e criaturas: uma análise sobre a relação entre memes de internet e propriedade intelectual". In: Intercom - Sociedade Brasileira de Estudos Interdisciplinares da Comunicação, XXXVIII Congresso Brasileiro de Ciências da Comunicação, Rio de Janeiro, RJ, 4-7 set. 2015.

CHAGAS, V., et al. "A política dos memes e os memes da política: proposta metodológica de análise de conteúdo de memes dos debates eleitorais de 2014". Intexto, Porto Alegre, UFRGS, no 38, p. 173-196, jan.-abr. 2017.

Chapman, J. Comparative media history. Manchester, UK: Polity Press, 2005.

Conboy, M. Journalism - A critical history. London, UK: Sage Publications Ltd, 2004.

Dalmonte, E.; FerReira, P. C.; CaRdoso, C. "Espalhamento midiático e profanação: uma análise de memes sobre os debates eleitorais de 2014". C\&S, São Bernardo do Campo, vol. 38, no 3, p. 217243, set.-dez. 2016.

DAVIS, J. L.; LOVE, T. P.; KILLEN, G. "Seriously funny: the political work of humor on social media". New Media \& Society, vol. 20, no 10 , p. 3.898-3.916, 2018.

DAVISON, P. The language of internet memes. In: MANDIBERG, M. (ed.). The social media reader. New York: New York University Press, 2012.

DAWKINS, R. The selfish gene. Oxford: Oxford University Press, 1976.

DYNEL, M. "'I has seen image macros!'. Advice animal memes as visual-verbal jokes". International Journal of Communication, vol. 10, p. 660-688, 2016.

FahmY, S.; IbRahim, O. "No, memes no! Digital persuasion in the \#MeToo Era". In: AEJMC Annual Conference, Toronto, Canadá, 2019.

Firdaus, S. N.; Ding, C.; SADEghian, A. "Topic specific emotion detection for retweet prediction". International Journal of Machine Learning and Cybernetics, vol. 10, p. 2.071-2.083, 2019.

Foss, S. K. Framing the study of visual rhetoric: toward a transformation of rhetorical theory. In: HiLL, C. A.; HeLMERS, M. (eds.). Defining visual rhetorics. Mahwah, NJ: Lawrence Erlbaum Associates, 2004.

GAL, N.; SHIFMAN, L.; KAMPF, Z. "'It Gets Better': Internet memes and the construction of collective identity". New Media \& Society, vol. 18, no 8, p. 1.698-1.714, 2015.

GarCíA-HUERTA, D. "Las imágenes macro y los memes de internet: posibilidades de estudio desde las teorías de la comunicación". Paakat: Revista de Tecnología y Sociedad, n 6, 2014.

Gómez-GarcíA, S., et al. "Constructing Donald Trump: mobile apps in the political discourse about the president of the United States". Comunicar, vol. 59, p. 49-59, 2019. 
HeISKANEN, B. "Meme-ing electoral participation". European Journal of American Studies, vol. 12, no 2, p. 1-26, 2017.

HighFIELD, T. "News via Voldemort: parody accounts in topical discussions on Twitter". New Media \& Society, vol. 18, no 9, p. 2.028-2.045, 2016.

Huntington, H. "Subversive memes: Internet memes as a form of visual rhetoric". Selected Papers of Internet Research, no 14, p. 23-26, 2013.

"Pepper spray cop and the American dream: using synecdoche and metaphor to unlock Internet memes' visual political rhetoric". Communication Studies, n 67, vol. 1, p. 77-93, 2016.

JACKSON, D.; THORSEN, E. "UK election analysis 2015: media, voters and the campaign". Project report. Bournemouth University, Poole, 2015.

JenKINS, H. Convergence culture: la cultura de la convergencia de los medios de comunicación. Barcelona: Paidós, 2008.

KADIR, S.; LoKmAn, A. "Memes: persuasive political warfare". Centre of Media and Information Warfare Studies (CMIWS), no 7, p. 31-35, 2013.

KNOBEL, M.; LANKSHEAR, C. Online memes, affinities, and cultural production. In: KNOBEL, M.; LANKSHEAR, C. (eds.). A new literacies sampler. New York: Peter Lang, 2007.

LU, S.; LUQIU, L. R. "Does political efficacy equally predict news engagement across countries? A multilevel analysis of the relationship among internal political efficacy, media environment and news engagement". New Media \& Society (online), 2019.

LYTTLE, J. "The effectiveness of humor in persuasion: the case of business ethics training". The Journal of General Psychology, nº 128, vol. 2, p. 206-216, 2001.

MANCera RUeda, A. "Estudio exploratorio de las estrategias de encuadre discursivo en memes humorísticos publicados en Twitter durante las elecciones generales de noviembre de 2019 celebradas en España". Dígitos, vol. 6, p. 197-207, 2020.

MANFRedi-SánChez, J.; AMAdo-SuÁRez, A.; WAisbord, S. "Presidential Twitter in the face of Covid-19: between populism and pop politics". Comunicar, vol. 29, nº 66, p. 83-94, 2021.

MÁRQUEZ, L. "¿Son los debates electorales la nueva Eurovisión? Análisis del seguimiento de dos eventos masivos a través de Twitter". Dígitos, n 3, p. 137-162, 2017.

Martínez-Rolán, X.; Piñeiro-Otero, T. "The use of memes in the discourse of political parties on Twitter: analysing the 2015 state of the nation debate". Communication \& Society, no 29, vol. 1, p. 145-159, 2016.

MazZoleni, G.; Bracciale, R. La politica pop online: i meme e le nuove sfide della comunicazione politica. Bologna: Il Mulino, 2019.

Meso-Ayerdi, K.; Mendiguren-Galdospín, T.; Pérez-Dasilva, J. "Memes políticos difundidos por usuarios de Twitter. Análisis de la jornada electoral del 26] de 2016". El Profesional de la Información, vol. 26, no 4, p. 673-682, 2017.

MILNER, R. M. "The world made meme: discourse and identity in participatory media culture". Phd. Dissertation of Communication Studies, University of Kansas, 2012.

"Pop polyvocality: Internet memes, public participation, and the Occupy Wall Street

Movement". International Journal of Communication, vol. 7, p. 2.357-2.390, 2013. 
MiLNER, R. M. "Memes are dead; long live memetics" (online). Culture Digitally, 27 oct. 2015. Disponible en: <https://culturedigitally.org/2015/10/01-memes-are-dead-long-live-memetics-byryan-m-milner>. Accesado el: 26 ago. 2016.

NAVARRo-SieRra, N.; QueVedo-Redondo, R. "El liderazgo político de la Unión Europea a través del ecosistema de aplicaciones móviles". Revista Prisma Social, vol. 30, p. 1-21, 2020.

Niven, D.; LICHTER, S. R.; AMUNDSON, D. "The political content of late night comedy". Harvard International Journal of Press/Politics, no 8, vol. 3, p. 118-133, 2003.

OCHOA, G. E. "De la caricatura al meme: las nuevas formas visuales de generar opinión a través del humor". Tesis Comunicación Social, Pontificia Universidad Católica de Ecuador, Ecuador, 2018.

PATO, I. "Podíamos. O cómo conquistar el Estado con memes y lágrimas". Playground, 19 ene. 2016.

PéRez-SAlAZAR, G. El meme en Internet: identidad y usos sociales. México: Fontamara, 2017.

PestaRino, J.; Winckler, G. "Memes políticos: apropiabilidad digital en la web 2.0". Artefacto Visual, vol. 3, no 4, p. 2.530-4.119, 2018.

POND, P.; LEWIS, J. "Riots and Twitter: connective politics, social media and framing discourses in the digital public sphere". Information, Communication \& Society, vol. 22, nº 2, p. 213-231, 2019.

Reichart, L.; Pegoraro, A.; Cruikshank, S. A. "Tweet, retweet, favorite: the impact of Twitter use on enjoyment and sports viewing". Journal of Broadcasting \& Electronic Media, vol. 63, no 1, p. 94-110, 2019.

Romero-CÁrCAMo, L. "Memes y opinión pública ¿una relación posible?". Diálogos de la Comunicación, n० 91, 2015.

Ruiz MARTínez, J. M. "Una aproximación retórica a los memes de internet". Revista Signa, no 27, p. 995-1.021, 2018.

ShifmAn, L. "An anatomy of a YouTube meme". New Media \& Society, vol. 14, no 2, p. 187-203, 2009.

. Memes in digital culture. Cambridge, MA: The MIT Press, 2014.

SHIFMAN, L.; THELWALL, M. "Assesing global diffusion with web memetics: the spread and evolution of a popular joke". Journal of the American Society for Information Science and Technology, no 60, p. 2.567-2.576, 2009.

STEPHENS, M. A history of news: from the drum to the satellite. England: Viking Penguin, 1988.

TAY, G. "Embracing LOLtics: popular culture, on-line political humor, and play". Phd Dissertation of Communication Studies, University of Canterbury, New Zealand, Christchurch, 2012.

USHER, B. "Me, you, and us: constructing political persona on social networks during the 2015 UK general election". Persona Studies, vol. 2, n² 2, p. 19-41, 2016.

VERA, E. "El meme como nexo entre el sistema educativo y el nativo digital: tres propuestas para la enseñanza de Lenguaje y Comunicación". Revista Educación y Tecnología, año 5, no 8, vol. 2, p. 115, 2016.

Webber, J.; SARLOS, S.; ECKHARDT, M. The cultural set up of comedy: affective politics in the United States post 9/11. Bristol: Intellect Ltd, 2013. 
Political memes as an online persuasive resource. Analysis of its impact during 2019 electoral debates in Spain

In the online politainment context, the use of political memes as a humorous and creative formula to configure the political image has become an increasingly common practice in electoral campaigns. Especially on the occasion of electoral debates, dissemination of political memes on social networks has captured the interest of scholars. This study takes into account the established political memes taxonomies and analyzes their persuasive capacity. Specifically, the research includes a quantitative analysis of the main memes spread on Twitter during the two electoral debates that took place in the 2019 electoral campaign in Spain: $4 \mathrm{~N}$ and $7 \mathrm{~N}$. The study uses the perspective of integrated framing (textual-visual) and is based on the persuasive power of memes in relation to the importance of each of the elements of rhetoric (pathos, ethos and logos), with the aim of analyzing as well the consequences on its virality and repercussion on the social audience.

Keywords: memes; social networks; electoral campaigns; Twitter; humor; Spain

\section{Resumo}

Memes políticos como recurso persuasivo online. Análise do seu impacto durante os debates eleitorais de 2019 na Espanha

No contexto da politainment online, o uso de memes políticos como uma fórmula humorística e criativa para configurar a imagem política tornou-se uma prática cada vez mais comum em campanhas eleitorais. Especialmente por ocasião dos debates eleitorais, a disseminação de memes políticos nas redes sociais conquistou o interesse dos acadêmicos. Este trabalho leva em consideração as taxonomias estabelecidas sobre os tipos de memes políticos e analisa sua capacidade de persuasão. Especificamente, a pesquisa inclui uma análise quantitativa dos principais memes espalhados no Twitter durante os dois debates eleitorais que ocorreram na campanha eleitoral de 2019 na Espanha: 4N e 7N. O estudo baseia-se na perspectiva do enquadramento integrado (textual-visual) e no estudo do poder persuasivo dos memes com base na importância de cada um dos elementos da retórica (pathos, ethos e logos), com o objetivo de analisar, também, as consequências de sua viralidade e repercussão no público social.

Palavras-chave: memes; redes sociais; campanhas eleitorais; Twitter; humor; Espanha

\section{Résumé}

Les mèmes politiques comme ressource en ligne convaincante. Analyse de son impact lors des débats électoraux de 2019 en Espagne

Dans le contexte du politainment en ligne, l'utilisation de mèmes politiques comme formule humoristique et créative pour façonner l'image politique est devenue une pratique de plus en plus courante dans les campagnes électorales. Surtout à I'occasion des débats électoraux, la diffusion de mèmes politiques dans les réseaux sociaux a suscité l'intérêt des universitaires. Cet article prend en considération les taxonomies établies sur les types de mèmes politiques et analyse leur capacité de persuasion. Plus précisément, la recherche comprend une analyse quantitative des principaux mèmes diffusés sur Twitter pendant les deux débats électoraux qui ont eu lieu lors de la campagne électorale de 2019 en Espagne : 4N et 7N. L'étude se fonde sur la perspective du cadrage intégré (textuel-visuel) et se base sur l'étude du pouvoir persuasif des mèmes en fonction de l'importance de chacun des éléments de la rhétorique (pathos, ethos et logos) afin d'analyser, également, les conséquences sur sa viralité et son impact sur l'audience sociale.

Mots-clés: mèmes; réseaux sociaux; campagnes électorales; Twitter; humour; Espagne

Artigo submetido à publicação em 8 de abril de 2020. Versão final aprovada em 5 de fevereiro de 2021.

Opinião Pública adota a licença Creative Commons CC-BY.

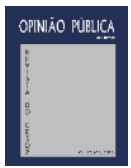

